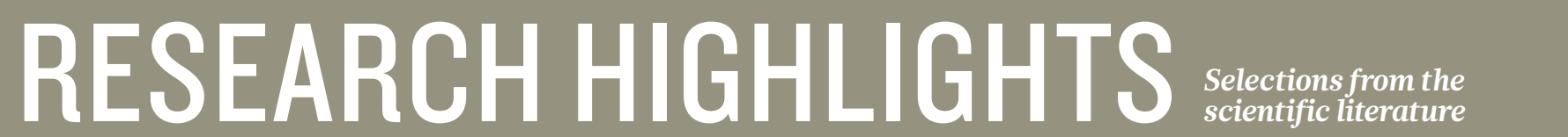

CANCER

\section{Immune-cell block halts brain tumour}

A drug that targets the white blood cells fostering brain tumours - rather than the cancer cells themselves shrinks tumours in mice.

The aggressive brain cancer known as glioblastoma is notoriously difficult to treat. Johanna Joyce at the Memorial Sloan-Kettering Cancer Center in New York and her colleagues gave mice with glioblastomas a drug that inhibits a cell-surface protein called colony-stimulating factor-1 receptor. This protein is expressed mainly on the white blood cells, or macrophages, that surround the tumour.

The 22 mice that did not receive the drug all died within 8 weeks. By contrast, $64 \%$ of the mice given the drug were still alive after 26 weeks. Surprisingly, the drug did not kill the macrophages but instead altered their gene expression, presumably turning off tumour-promoting functions.

Nature Med. 19, 1264-1272 (2013)

ZOOLOGY

\section{Shining light on} cold turtles

Freshwater turtles can survive the winter at the bottom of frozen lakes despite a complete lack of oxygen. But they do not, as some have suggested, fall into a coma when hibernating, according to Jesper Madsen of Aarhus University in Denmark and his colleagues.

Madsen and his team submerged Trachemys scripta turtles (pictured) in cold, oxygen-depleted water to put them into false hibernation. The animals still responded

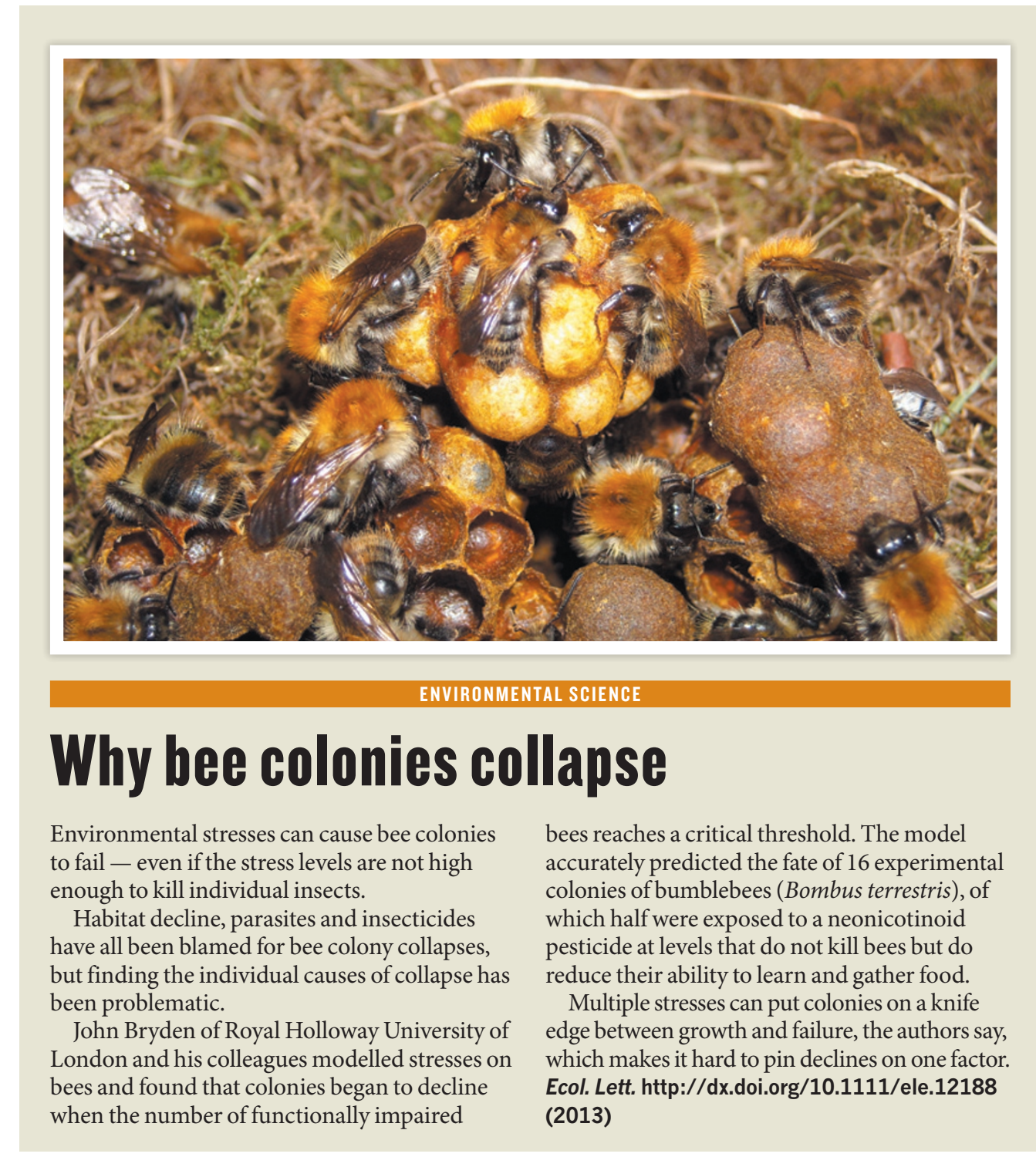

to light and increased

temperatures, but not to vibrations or increased oxygen levels. The results suggest that hibernating turtles are in a low-energy but vigilant state.

The brains of chemically anaesthetized turtles also responded to light, indicating that these animals have adapted to remain responsive to this stimulus even when other body systems are shut down.

Biol. Lett. 9, 20130602 (2013)

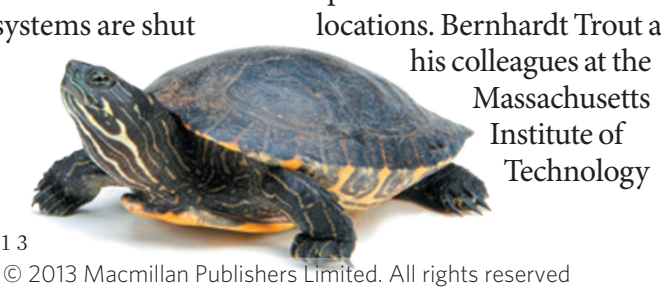
his colleagues at the

\section{DRUG MANUFACTURINE}

\section{From synthesis to pill without pause}

A factory that produces a continuous stream of drug tablets from the raw ingredients could save time and money over traditional stop-start methods, which spread manufacture over many locations. Bernhardt Trout and in Cambridge report the first example of such a plant, an 18-square-metre factory that produces the hypertension drug aliskiren (developed by Novartis, which funded the project).

Chemical building blocks flow in at one end, followed by a series of reactions and separations in which the drug is synthesized, crystallized, dried and coated to produce tablets at the other.

Angew. Chem. Int. Edn http://dx.doi.org/10.1002/ anie.201305429 (2013) 